\title{
BMJ Open Experimentation with e-cigarettes as a smoking cessation aid: a cross-sectional study in 28 European Union member states
}

\author{
Filippos T Filippidis, ${ }^{1}$ Anthony A Laverty, ${ }^{1}$ Constantine I Vardavas ${ }^{2}$
}

To cite: Filippidis FT, Laverty AA, Vardavas $\mathrm{Cl}$. Experimentation with e-cigarettes as a smoking cessation aid: a crosssectional study in 28 European Union member states. BMJ Open 2016;6: e012084. doi:10.1136/ bmjopen-2016-012084

- Prepublication history and additional material is available. To view please visit the journal (http://dx.doi.org/ 10.1136/bmjopen-2016012084).

Received 28 March 2016 Revised 25 July 2016 Accepted 12 September 2016

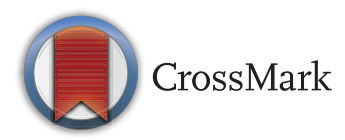

${ }^{1}$ Department of Primary Care and Public Health, School of Public Health, Imperial College London, London, UK ${ }^{2}$ Clinic of Social and Family Medicine, School of Medicine, University of Crete, Heraklion, Greece

Correspondence to Dr Filippos T Filippidis; f.filippidis@imperial.ac.uk

\section{ABSTRACT}

Objectives: To describe patterns of experimentation with electronic cigarettes as a smoking cessation aid, their self-reported impact on smoking cessation and to identify factors associated with self-reported successful quit attempts within the European Union (EU).

Design: A cross-sectional study.

Setting: 28 European Union member states.

Methods: We analysed data from wave 82.4 of the Special Eurobarometer survey, collected in December 2014 from all $28 \mathrm{EU}$ member states. The total sample size was $n=27801$ individuals aged $\geq 15$ years; however, our analyses were conducted in different subgroups with sample sizes ranging from $\mathrm{n}=470$ to $\mathrm{n}=9363$. Data on e-cigarette experimentation and its self-reported impact on smoking cessation were collected. Logistic regression models were used to assess factors associated with experimentation of e-cigarettes as cessation aids and with successful quitting. Logistic regression was also used to assess changes in the use of e-cigarettes as cessation aids between 2012 (using data from wave 77.1 of the Eurobarometer) and 2014 in each member state.

Results: E-cigarettes were often experimented with as a cessation aid, especially among younger smokers $(O R=5.29)$ and those who reported financial difficulties ( $O R=1.33)$. In total, $10.6 \%$ of those who had ever attempted to quit smoking and $27.4 \%$ of those who did so using a cessation aid had experimented with e-cigarettes as a cessation aid. Among those who had used e-cigarettes as a cessation aid, those with higher education were more likely to have been successful in quitting $(O R=2.23)$.

There was great variation in trends of use of e-cigarette as a cessation aid between member states.

Conclusions: Experimentation with e-cigarettes as a potential cessation aid at a population level has increased throughout the EU in recent years, and certain population groups are more likely to experiment with them as cessation aids. Research on the potential population impact of these trends is imperatively needed.

\section{Strengths and limitations of this study}

- The study has a large and representative sample of respondents aged 15 years and older across 28 European Union (EU) member states; therefore, it provides reliable data for the entire EU.

- However, data were self-reported and could not be verified with objective measurements.

- The study design was cross-sectional; therefore, causal interpretations should be made with caution.

\section{INTRODUCTION}

Electronic cigarettes (e-cigarettes) have increased in popularity among smokers, ex-smokers and non-smokers in recent years. ${ }^{1-3}$ The e-cigarette industry often promotes them as healthier alternatives which may help smokers to quit or reduce smoking, as well as to be used in places where regular smoking is prohibited. ${ }^{4}$ The regulation of e-cigarettes has varied among different countries. In the USA, the regulatory authority of the Food and Drug Administration was extended in 2016 to include the manufacture, import, packaging, labelling, advertising, promotion, sale and distribution of e-cigarettes. ${ }^{5}$ The European Union (EU), on the other hand, regulates e-cigarettes initially on their nicotine content, based on which they come under the Consumers Products Directive (for $0 \mathrm{mg} / \mathrm{mL}$ nicotine concentrations), the Tobacco Products Directive (TPD) (nicotine concentration $>0$ but $<20 \mathrm{mg} / \mathrm{mL}$ ) or as a pharmaceutical device (if the product receives medical licensing). All EU member states were required to comply with the revised Tobacco Products Directive by 20 May 2016, but may have followed different regulatory approaches in previous years. ${ }^{6}$

Central to the ongoing global debate on the public health impact of e-cigarettes is 
whether they are effective or not in aiding smoking cessation or lead to a reduction or increase in use of tobacco products. This is of critical importance as this might determine whether e-cigarettes result in a net harm or benefit on population health. ${ }^{7}$ While some studies suggest that e-cigarettes may be potentially effective in promoting smoking cessation and reducing cigarette consumption, ${ }^{8} 9$ many others have failed to show any benefit, with a recent meta-analysis indicating that overall e-cigarette use was associated with significantly lower odds of quitting smoking. ${ }^{10}$

The issue is further complicated by the lack of clarity on the degree to which e-cigarettes are experimented with as smoking cessation devices and how they may impact tobacco use at a population level, ${ }^{11}$ which highlights the need for studies with large and representative samples of populations. This is particularly important considering the sharp increase in e-cigarette use in Europe recently. ${ }^{3}$ Providing up-to-date estimates can be particularly useful for policies and planning in tobacco control. In addition to the issue of their effectiveness overall, there are also questions around whether certain groups may be more likely to be successful in quitting with e-cigarettes. This would parallel findings that traditional stop-smoking services are less likely to be effective in certain groups. ${ }^{12}$

Hence, we conducted a secondary analysis of 2012 and 2014 Eurobarometer data in order to identify the extent to which e-cigarettes may be experimented with as a smoking cessation device, explore changes between 2012 and 2014 and identify sociodemographic factors associated with experimentation of e-cigarettes as a cessation aid and with self-reported successful quit attempts following e-cigarette use.

\section{METHODS}

\section{Data source}

We conducted a secondary analysis of data from wave 82.4 of the Eurobarometer survey, ${ }^{13}$ collected in $28 \mathrm{EU}$ member states in November-December 2014. A multistage sampling design was employed in order to collect samples representative of the population aged $\geq 15$ years, both at an EU level and at the member state level. Primary sampling units (PSU) were selected from each region of each country, proportional to population size. Subsequently, a sample of starting addresses was randomly selected in each PSU and households were systematically selected through a standard random route starting from these addresses. Eurobarometer does not publish response rates, but post-stratification and population size weighting were applied in each country/region, resulting in nationally representative samples in terms of age, gender and area of residence. Face-to-face interviews were used to record self-reported data on tobacco use and sociodemographic characteristics; all interviews were conducted at participants' homes and in the local language. The total sample was $n=27801$ individuals from all $28 \mathrm{EU}$ member states. Detailed data on the final sample, the sampling methodology and the questionnaire have been made available in the official Eurobarometer report. ${ }^{14} \mathrm{We}$ also used data from wave 77.1 of Eurobarometer (February-March 2012; $\mathrm{n}=26$ 751) to conduct comparisons with 2012. The data sets were publicly available and all data were de-identified; thus, no ethical approval was required.

\section{Measures}

\section{E-cigarette use}

Current and ever e-cigarette use was assessed with the question "Regarding the use of electronic cigarettes or any similar electronic devices (e-shisha, e-pipe), which of the following statements applies to you?" and responses included "You currently use electronic cigarettes or similar electronic devices (eg, e-shisha, e-pipe)"; "You used them in the past, but no longer use them"; "You tried them in the past but no longer use them"; "You have never used them"; and "Don't know". The first response was considered as an indication of current use, while any of the first three responses was considered 'ever use of e-cigarettes'.

\section{Cigarette smoking}

All participants were asked "Regarding smoking cigarettes, cigars or a pipe, which of the following applies to you?". Responses included "You currently smoke" (ie, current smokers); "You used to smoke but you have stopped" (ie, ex-smokers); and "You have never smoked" (ie, never smokers).

\section{Use of cessation aids}

Ex-smokers and current smokers who had ever tried to quit (assessed using the question "Have you ever tried to quit smoking?") were asked "Which of the following did you use in order to quit or to try to quit smoking?". Responses included "nicotine replacement medications (like nicotine gum, patch or inhaler) or other medications"; "support from the doctor or other health professional or special stop-smoking services such as clinics or specialists"; "telephone quit line services"; "internet quit line services"; "alternative therapies such as acupuncture or hypnosis"; "oral tobacco (snus) chewing or nasal tobacco (snuff)"; "electronic cigarettes or any similar device"; "smokeless cigarettes (other than electronic)"; "you quit or you tried to quit without assistance"; and 'other'. Each participant could report having used multiple cessation aids. Those who responded "don't know" were excluded from this analysis $(n=291)$.

\section{Effects of e-cigarette use on cigarette smoking}

Respondents who responded that they had ever used ecigarettes and had ever smoked tobacco were asked whether the use of electronic cigarettes or any similar device had helped them to stop or reduce their tobacco consumption. Response options included "Yes, you stopped smoking tobacco completely"; "Yes, you stopped 
smoking tobacco for a while but started again"; "Yes, you reduced your tobacco smoking but did not stop"; No, you did not reduce your tobacco smoking at all"; "No and actually you increased your tobacco smoking". Those who reported that they stopped smoking tobacco for a while or permanently were considered successful quitters following e-cigarette use. They are referred to here as 'self-reported successful quitters.'

\section{Sociodemographic data}

Data were collected on participants' age (15-24; 25-39; $40-54$; and $\geq 55$ years), gender (male; female), age at which they stopped full-time education: $(\leq 15 ; 16-19$ and $\geq 20$ years old) and their difficulties in paying bills during the past 12 months (almost never/never; and from time to time/most of the time), which was used as a proxy of financial difficulties.

\section{Statistical analysis}

Descriptive results are presented as percentages with 95\% CIs for categorical values and means with $95 \%$ CI for continuous variables. Multilevel logistic regression results are presented as adjusted ORs with 95\% CI. For our analyses, we used the following subsamples: former smokers and current smokers who said that they had ever tried to quit $(\mathrm{n}=9363)$; former smokers and current smokers who had ever used a cessation aid $(n=3407)$; ever cigarette smokers who were also ever e-cigarette users ( $n=2333)$; ever cigarette smokers who had also experimented with e-cigarettes as a cessation aid $(\mathrm{n}=681)$; and former smokers who had ever used ecigarettes $(n=470)$ (see online supplementary table $\mathrm{S} 1$ ). All regression analyses included sociodemographic factors-gender; age; education; and difficulty in paying bills-as independent variables. Adjusted multilevel logistic regression analyses-with country being the higher level variable-were performed for each of the following outcomes:

1. Experimentation with e-cigarettes as a smoking cessation aid, separately among ex/current smokers who had ever tried to quit and among the subset of them who reported having used at least one cessation aid in the past.

2. Having successfully quit smoking following the use of e-cigarettes (self-reported), separately among those who had ever used e-cigarettes and among those who had experimented with e-cigarettes specifically as a cessation aid.

Finally, an unadjusted logistic regression model was fitted for each country to assess the change in the odds of having experimented with e-cigarette as a cessation aid between 2012 and 2014. We used weights for each survey year, but did not include sociodemographic variables in the model, due to the relatively small sample sizes by country. Response options for e-cigarette and smokeless cigarette were grouped together in the 2012; thus, we included smokeless cigarettes in both waves for consistency in the comparison, also considering that the distinction between the two products may not be clear among consumers.

All analyses were performed with Stata V.13.0; weights provided in the official Eurobarometer data set were used to account for the multistage sampling of the survey, and observations with missing values were excluded from the analysis.

\section{RESULTS}

Sociodemographic factors associated with experimentation of e-cigarettes as a smoking cessation aid

Among current and ex-smokers who had ever attempted to quit smoking, $10.6 \%$ (95\% CI $9.4 \%$ to $11.7 \%$ ) had tried to do so with e-cigarettes, while $61.4 \%$ (95\% CI $59.8 \%$ to $63.1 \%$ ) did not use any smoking cessation aid. Within the subgroup of respondents who reported the use of any cessation aid, the proportion who had experimented with e-cigarettes to quit smoking was $27.4 \%$ (95\% CI $24.7 \%$ to $30.1 \%$ ). Furthermore, among current smokers who reported using a smoking cessation aid in the past year, $43.6 \%(95 \%$ CI $37.5 \%$ to $50.0 \%$ ) reported experimenting with e-cigarettes to try to quit smoking.

As depicted in table 1, younger participants (1524-year-olds) were more likely than those aged 55+ to have experimented with e-cigarettes as cessation aids both among those who had tried to quit (OR=5.29; $95 \%$ CI 3.89 to 7.19) and among those who had tried to quit with the use of a cessation aid (OR=6.43; $95 \%$ CI 3.07 to 12.23). Among those who had tried to quit smoking in the past, participants who reported facing financial difficulties were more likely to have experimented with ecigarettes as cessation aids ( $\mathrm{OR}=1.33 ; 95 \%$ CI 1.11 to $1.59)$ in comparison to those who reported that they were not facing financial difficulties. This association, however, was not statistically significant either in the subgroup of current smokers or in the subgroup of respondents who had used a cessation aid to quit in the past (table 1).

\section{Changes in e-cigarette and smokeless cigarette use as cessation aids between 2012 and 2014}

Respondents who had attempted to quit smoking-successfully or not-in the EU were more likely to report that they have experimented with e-cigarettes (or/and smokeless cigarettes) as cessation aids in 2014 compared to $2012(8.2 \%$ in $2014 ; 3.4 \%$ in 2012 ; OR $=3.22 ; 95 \%$ CI 2.63 to 3.94$)$. The increase was statistically significant in 16 member states, but the magnitude of these changes varied greatly between countries (figure 1). Results for Croatia are not presented, as the country was not included in the survey in 2012. Results for Portugal are also not presented, because the number of respondents who had used e-cigarettes (or/and smokeless cigarettes) as cessation aids in the first wave was $<10$ and hence the 95\% CI was extremely wide. 
Table 1 Sociodemographic factors associated with the use of e-cigarettes as a smoking cessation aid in the EU

\begin{tabular}{|c|c|c|c|c|}
\hline & $\begin{array}{l}\text { Among those who } \\
\text { have ever tried to } \\
\text { quit smoking } \\
\text { aOR }(95 \% \mathrm{Cl}) \\
\mathrm{n}=9363\end{array}$ & $\begin{array}{l}\text { Among current } \\
\text { smokers who have } \\
\text { ever tried to quit } \\
\text { smoking } \\
\text { aOR }(95 \% \mathrm{Cl}) \\
\mathrm{n}=3908\end{array}$ & $\begin{array}{l}\text { Among former } \\
\text { smokers } \\
\text { aOR }(95 \% \mathrm{Cl}) \\
\mathrm{n}=5455\end{array}$ & $\begin{array}{l}\text { Among those who } \\
\text { have ever used any } \\
\text { cessation aid to quit } \\
\text { smoking } \\
\text { aOR }(95 \% \mathrm{Cl}) \\
\mathrm{n}=3407\end{array}$ \\
\hline \multicolumn{5}{|l|}{ Age (years) } \\
\hline$\geq 55$ & 1.00 & 1.00 & 1.00 & 1.00 \\
\hline $40-54$ & 2.99 (2.40 to 3.74$)$ & $1.73(1.33$ to 2.25$)$ & 4.03 (2.57 to 6.32$)$ & 2.66 (2.09 to 3.38$)$ \\
\hline 25-39 & 3.51 (2.78 to 4.43$)$ & 1.91 (1.45 to 2.51$)$ & 5.45 (3.43 to 8.66$)$ & 3.37 (2.61 to 4.36$)$ \\
\hline $15-24$ & 5.29 (3.89 to 7.19$)$ & 2.69 (1.89 to 3.82$)$ & 6.13 (3.07 to 12.23$)$ & 6.43 (4.48 to 9.23$)$ \\
\hline \multicolumn{5}{|l|}{ Gender } \\
\hline Female & 1.00 & 1.00 & 1.00 & 1.00 \\
\hline Male & $1.01(0.86$ to 1.19$)$ & 0.98 (0.81 to 1.18$)$ & 1.30 (0.93 to 1.81$)$ & $0.94(0.78$ to 1.12$)$ \\
\hline \multicolumn{5}{|l|}{ Difficulties paying bills } \\
\hline Never/almost never & 1.00 & 1.00 & 1.00 & 1.00 \\
\hline $\begin{array}{l}\text { From time to time/ } \\
\text { most of the time }\end{array}$ & $1.33(1.11$ to 1.59$)$ & $1.01(0.82$ to 1.24$)$ & 1.62 (1.13 to 2.33$)$ & $1.18(0.97$ to 1.44$)$ \\
\hline \multicolumn{5}{|c|}{ Age when stopped education (years) } \\
\hline Up to 15 & 1.00 & 1.00 & 1.00 & 1.00 \\
\hline $16-19$ & $1.32(1.00$ to 1.74$)$ & $1.26(0.92$ to 1.74$)$ & $1.75(0.90$ to 3.41$)$ & $1.20(0.88$ to 1.64$)$ \\
\hline$\geq 20$ & $1.01(0.75$ to 1.36$)$ & $1.07(0.76$ to 1.50$)$ & 1.55 (0.78 to 3.09$)$ & $0.92(0.66$ to 1.28$)$ \\
\hline
\end{tabular}

\section{Self-reported impact of e-cigarette use on tobacco use}

Among respondents who reported ever having used both tobacco and e-cigarettes, $50.7 \%$ reported that ecigarettes did not help them reduce smoking or that they actually smoked more after trying them, 21.8\% reported that they helped them reduce smoking consumption, $14.4 \%$ reported that e-cigarettes helped them to quit completely, while $13.1 \%$ reported that they quit for a while but then relapsed. The proportion of selfreported successful quitters among respondents who explicitly reported having experimented with e-cigarettes in order to quit was $23.5 \%$ (table 2).

\section{Factors associated with successful quitting smoking among e-cigarette users}

Logistic regression analyses revealed that age, gender and financial difficulties were not associated with selfreported successfully quitting smoking among any of the two subgroups that were examined (table 3). Higher education was positively associated with self-reporting a successful quit attempt among those who experimented with e-cigarettes as a cessation aid $(\mathrm{OR}=2.23 ; 95 \%$ CI 1.05 to 4.75 ); this association was less clear in the other group.

\section{DISCUSSION}

Our analysis of representative data from $28 \mathrm{EU}$ member states has found that e-cigarettes were being experimented with by $\sim 1$ in 10 smokers and one in four of those who used a cessation aid to quit had experimented with e-cigarettes, with higher percentages noted among younger smokers. It is interesting to note that experimentation with e-cigarettes as a cessation aid has more than doubled throughout the EU in just 2 years, although one in two among those who did so reported that they did not help them reduce smoking or that they actually smoked more after trying them.

More than 4 of 10 current smokers who made a quit attempt during the year before the survey had experimented with e-cigarettes as a way to stop smoking, making it the most popular cessation aid within this group. This finding highlights the increasing popularity of e-cigarettes, despite the lack of scientific evidence or recommendation, regarding their use as cessation aids. It also serves as a reminder that advertising ${ }^{4}$ may overshadow scientific evidence, ${ }^{10}$ especially in novel products, such as e-cigarettes.

There was some indication that people of lower socioeconomic status were more likely to have experimented with e-cigarettes as cessation aids. This may reflect limited access to evidence-based smoking cessation products and methods among smokers with financial difficulties, who may turn to e-cigarettes which are commercially available and do not require visits to healthcare professionals, with the additional costs that these may incur. Indeed, it has been previously shown that smokers are more likely to use evidence-based cessation aids when costs are covered by the state ${ }^{15}$ and that cost is an important barrier for the use of cessation aids, especially in young smokers. ${ }^{16}$ Among those who experimented with e-cigarettes in order to quit smoking, respondents with a higher educational level were more likely to report that they were successful in quitting. This 
Figure 1 Change in use of e-cigarettes as cessation aids between 2012 and 2014 in the EU (OR and 95\% Cl). *Data for Croatia not shown, as it was not included in the 2012 wave. Data for Portugal not shown due to the extremely wide Cl. EU, European Union.

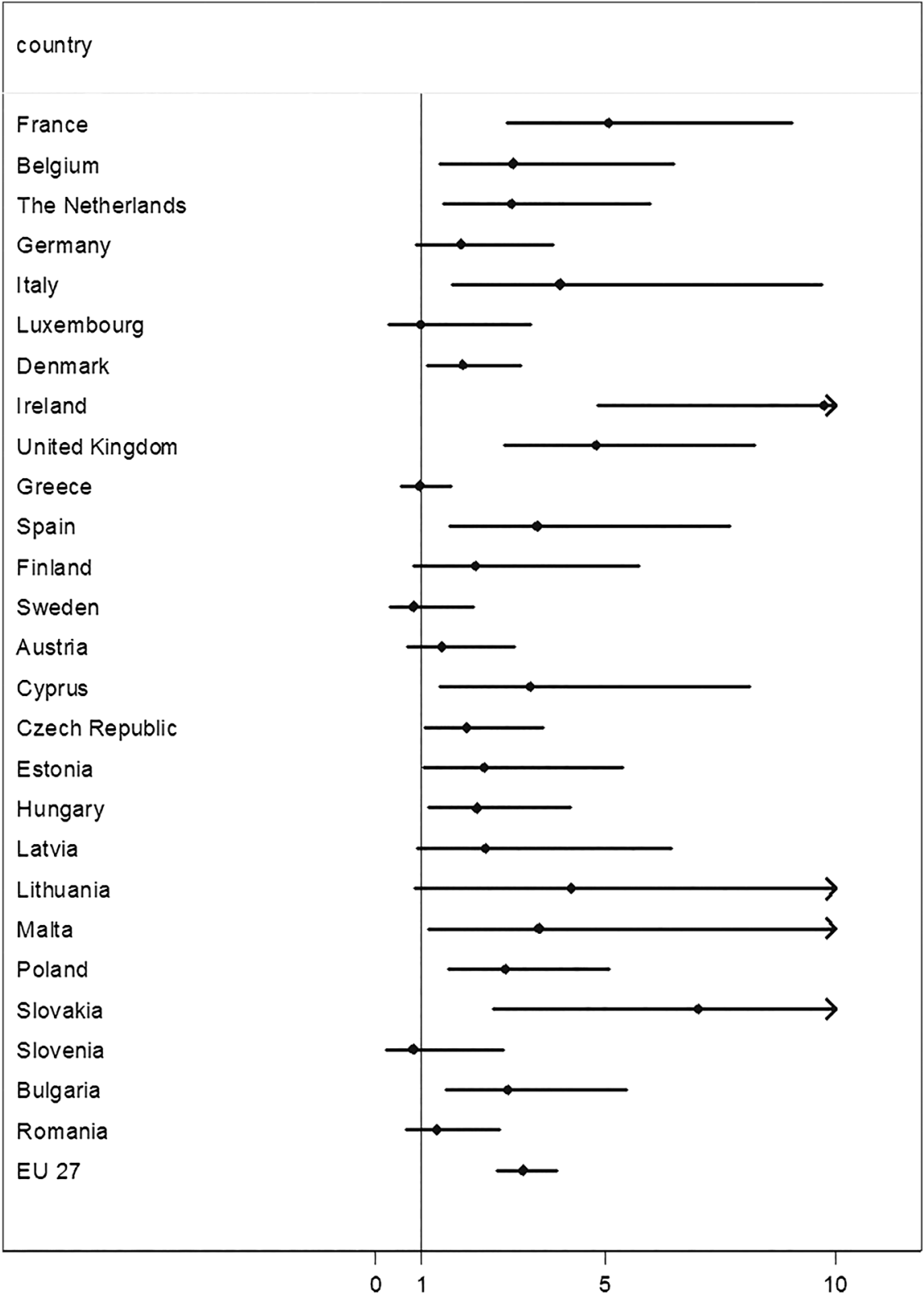

Table 2 Self-reported impact of e-cigarette use on tobacco use in the EU

\begin{tabular}{|c|c|c|c|}
\hline & $\begin{array}{l}\text { Among those who have } \\
\text { tried e-cigarettes } \\
\%(95 \% \mathrm{Cl}) \\
\mathrm{n}=2333\end{array}$ & $\begin{array}{l}\text { Among those who have used } \\
\text { e-cigarettes as a cessation aid } \\
\%(95 \% \mathrm{Cl}) \\
\mathrm{n}=681\end{array}$ & $\begin{array}{l}\text { Among ex-smokers who } \\
\text { have tried e-cigarettes } \\
\%(95 \% \mathrm{Cl}) \\
\mathrm{n}=470\end{array}$ \\
\hline $\begin{array}{l}\text { Stopped smoking tobacco } \\
\text { completely }\end{array}$ & $14.4(12.0$ to 16.8$)$ & 23.5 (18.3 to 28.6$)$ & 57.1 (49.4 to 64.4$)$ \\
\hline $\begin{array}{l}\text { Stopped smoking tobacco } \\
\text { for a while, but started } \\
\text { again }\end{array}$ & 13.1 (10.7 to 15.5$)$ & 21.7 (16.6 to 26.8 ) & 6.6 (3.9 to 11.1$)$ \\
\hline $\begin{array}{l}\text { Reduced smoking but did } \\
\text { not stop }\end{array}$ & 21.8 (19.0 to 24.6 ) & 30.5 (24.8 to 36.2 ) & 9.3 (5.9 to 14.2$)$ \\
\hline $\begin{array}{l}\text { Did not reduce or } \\
\text { increased tobacco } \\
\text { smoking }\end{array}$ & 50.7 (47.4 to 54.0$)$ & 24.3 (19.7 to 28.9 ) & $27.0(20.7$ to 34.4$)$ \\
\hline
\end{tabular}


Table 3 Factors associated with successful smoking cessation among e-cigarette in the EU

\begin{tabular}{|c|c|c|}
\hline & $\begin{array}{l}\text { Among those who have tried } \\
\text { e-cigarettes } \\
\text { aOR }(95 \% \mathrm{Cl}) \\
\mathrm{n}=2261\end{array}$ & $\begin{array}{l}\text { Among those who have used } \\
\text { e-cigarettes as a cessation aid } \\
\text { aOR }(95 \% \mathrm{Cl}) \\
\mathrm{n}=665\end{array}$ \\
\hline \multicolumn{3}{|l|}{ Age (years) } \\
\hline$\geq 55$ & 1.00 & 1.00 \\
\hline $40-54$ & $0.73(0.50$ to 1.05$)$ & $0.59(0.35$ to 1.01$)$ \\
\hline 25-39 & 0.94 (0.66 to 1.32$)$ & $0.86(0.51$ to 1.46$)$ \\
\hline $15-24$ & 0.87 (0.58 to 1.33$)$ & $0.54(0.26$ to 1.11$)$ \\
\hline \multicolumn{3}{|l|}{ Gender } \\
\hline Female & 1.00 & 1.00 \\
\hline Male & $1.22(0.95$ to 1.57$)$ & $1.30(0.89$ to 1.90$)$ \\
\hline \multicolumn{3}{|l|}{ Difficulties paying bills } \\
\hline Never/almost never & 1.00 & 1.00 \\
\hline From time to time/most of the time & $0.88(0.68$ to 1.14$)$ & $0.88(0.59$ to 1.29$)$ \\
\hline \multicolumn{3}{|l|}{ Age when stopped education (years) } \\
\hline Up to 15 & 1.00 & 1.00 \\
\hline $16-19$ & $1.21(0.74$ to 1.95$)$ & $1.45(0.70$ to 2.97$)$ \\
\hline$\geq 20$ & 1.60 (0.97 to 2.62$)$ & 2.23 (1.05 to 4.75$)$ \\
\hline
\end{tabular}

is consistent with findings from earlier studies, in which more educated smokers were more likely to try to quit and be successful in quitting, ${ }^{17} 18$ even though our study did not have objective measures of quitting to validate the respondents' claims. In addition to that, the experimentation of e-cigarette as a cessation aid could not be linked to a particular quit attempt within the context of the study.

The proportion of e-cigarette users who reported that e-cigarette use helped them to quit smoking completely was $14.4 \%$, but reached $23.5 \%$ among those who explicitly mentioned that they experimented with them for the purpose of quitting smoking. These numbers suggest that a proportion of e-cigarette experimenters may quit, but its relative effectiveness as a cessation aid compared to well-established aids ${ }^{19}$ cannot be estimated with this data set. Available evidence on the effectiveness of interventions such as nicotine replacement therapy (NRT) point to the additional benefits of behavioural support, ${ }^{20}$ and the interaction of e-cigarette use with this remains to be seen. Self-reported outcomes of smoking cessation can be ambiguous, especially when there is no clearly defined time frame of complete abstinence from cigarette smoking. Moreover, there may be recall and wish bias in reporting use of e-cigarette as a cessation aid, which might inflate the proportion of successful quitters among the group that explicitly reported using them to stop smoking. In any case, the patterns of use among e-cigarette users varied widely, as they were not known to be following a protocol for smoking cessation; as a result, the reported outcomes cannot be attributed to a specific pattern of use, for example, daily or occasional, dual or exclusive use. This may be an important consideration, as it has previously been shown that frequency of e-cigarette use and device type could influence the outcome of a smoking cessation or reduction attempt. ${ }^{21-23}$

There was a significant increase in the proportion of people who experimented with e-cigarettes as a cessation aid among those who had ever tried to quit within only 2 years. Considering that many of the respondents could have quit smoking several years before the surveys, when e-cigarettes did not exist, the recorded increase highlights the extent of the popularity of e-cigarettes in the past few years. We found wide variation in the trends of e-cigarette use as a cessation aid between EU member states, with the majority of them showing a statistically significant increase. The differences between countries may be attributed to different regulatory approaches towards e-cigarettes, which lead to variation in the overall use among the population, ${ }^{3} 24$ as well as to different policies with regard to the cost of cessation aids and whether this is partly or fully covered by the public healthcare system in each country. ${ }^{15}$ Following the implementation of the TPD across the EU, such differences in policies may be attenuated; therefore, it is important to continue monitoring the trends in the use of e-cigarettes in all member states and explore whether this variation will continue to exist.

\section{Strengths and limitations}

This is the largest study to assess the reported experimentation with e-cigarettes as smoking cessation devices in a representative sample of respondents aged 15 years and older across 28 EU member states. The large sample size also allowed us to adjust for several confounding factors and minimise residual confounding. We must state, however, that the detected associations are useful for descriptive purposes and can generate hypotheses, but no definitive conclusions can be drawn 
from such a survey, especially considering that data were self-reported, without objective measurements that could validate reports of quitting or of reduction in cigarette smoking. We additionally do not have information on how long self-reported quitters have reduced or abstained from tobacco smoking. Moreover, we were not able to directly compare e-cigarettes with other evidence-based cessation methods (such as NRT in terms of outcomes), which limits our ability to make conclusions regarding the effectiveness of e-cigarettes in smoking cessation. Finally, causal relationships cannot be evaluated due to the cross-sectional design of the Eurobarometer survey.

\section{CONCLUSIONS}

The questions regarding the potential role of e-cigarettes in smoking cessation, their efficacy and public health implications are pressing, as the popularity of e-cigarettes is rapidly increasing. Our analyses of the most recent Special Eurobarometer data revealed increases in experimentation with e-cigarettes as a smoking cessation device across the EU, but with ambiguous results. Continued monitoring of the role of e-cigarettes in Europe and beyond remains essential in order to assess trends in their use and inform national policies, especially as the regulatory landscape will be influenced by the implementation of the TPD.

Acknowledgements The authors would like to thank Dr Israel Agaku for his contribution and comments on the manuscript.

Contributors FTF conceived and conducted the data analysis. FTF, AAL and CIV all contributed to data interpretation and manuscript preparation.

Funding This work was supported by a grant from the European Commission (Horizon2020 HCO-6-2015; EUREST-PLUS: 681109; Vardavas).

\section{Competing interests None declared.}

Provenance and peer review Not commissioned; externally peer reviewed.

Data sharing statement The data set is publicly available at the GESIS Data Archive, DOI: doi:10.4232/1.12265.

Open Access This is an Open Access article distributed in accordance with the Creative Commons Attribution Non Commercial (CC BY-NC 4.0) license, which permits others to distribute, remix, adapt, build upon this work noncommercially, and license their derivative works on different terms, provided the original work is properly cited and the use is non-commercial. See: http:// creativecommons.org/licenses/by-nc/4.0/

\section{REFERENCES}

1. Beard E, Brown J, McNeill A, et al. Has growth in electronic cigarette use by smokers been responsible for the decline in use of licensed nicotine products? Findings from repeated cross-sectional surveys. Thorax 2015;70:974-8.

2. Grana R, Benowitz N, Glantz SA. E-cigarettes: a scientific review. Circulation 2014;129:1972-86.

3. Filippidis FT, Laverty AA, Gerovasili V, et al. Two-year trends and predictors of e-cigarette use in 27 European Union member states. Tob Control 2016. [Epub ahead of print]. doi: 10.1136/ tobaccocontrol-2015-052771

4. Grana RA, Ling PM. "Smoking revolution": a content analysis of electronic cigarette retail websites. Am J Prev Med 2014;46:395-403.

5. U.S. Food and Drug Administration. Vaporizers, E-Cigarettes, and other Electronic Nicotine Delivery Systems (ENDS). Secondary
Vaporizers, E-Cigarettes, and other Electronic Nicotine Delivery Systems (ENDS) 2016. http://www.fda.gov/TobaccoProducts/ Labeling/ProductsIngredientsComponents/ucm456610. htm\#regulation

6. European Commission. Directive of the European Union on the approximation of the laws, regulations and administrative provisions of the Member States concerning the manufacture, presentation and sale of tobacco and related products and repealing Directive 2001/37/EC. Secondary Directive of the European Union on the approximation of the laws, regulations and administrative provisions of the Member States concerning the manufacture, presentation and sale of tobacco and related products and repealing Directive 2001/37/EC. http://ec.europa. eu/health/tobacco/docs/dir_201440_en.pdf (accessed 25 Sep 2015).

7. Kalkhoran S, Glantz SA. Modeling the health effects of expanding e-cigarette sales in the United States and United Kingdom: a Monte Carlo analysis. JAMA Intern Med 2015;175:1671-80. doi: 10.1001/ jamainternmed.2015.4209[published Online First: Epub Date]l.

8. Brown J, Beard E, Kotz D, et al. Real-world effectiveness of e-cigarettes when used to aid smoking cessation: a cross-sectional population study. Addiction 2014;109:1531-40.

9. McRobbie H, Bullen C, Hartmann-Boyce J, et al. Electronic cigarettes for smoking cessation and reduction. Cochrane Database Syst Rev 2014;(12):CD010216.

10. Kalkhoran S, Glantz SA. E-cigarettes and smoking cessation in real-world and clinical settings: a systematic review and meta-analysis. Lancet Respir Med 2016;4:116-28.

11. Bernstein SL. Electronic cigarettes: more light, less heat needed. Lancet Respir Med 2016;4:85-7.

12. National Centre for Smoking Cessation and Training (NCSCT). Stop Smoking Services and Health Inequalities, 2013. http://www.ncsct. co.uk/usr/pub/NCSCT_briefing_effect_of_SSS_on_health_ inequalities.pdf

13. European Commission. Eurobarometer 82.4, November-December 2014. GESIS Data Archive: ZA5933, data set version 5.0.0 (2014). Brussels: TNS OPINION \& SOCIAL, 2014.

14. European Commission. Special Eurobarometer 429. Attitudes of Europeans towards tobacco, 2015. http://ec.europa.eu/public_ opinion/archives/ebs/ebs_429_en.pdf

15. Filippidis FT, Gerovasili V, Vardavas Cl, et al. Determinants of use of smoking cessation aids in 27 European countries. Prev Med 2014;65:99-102.

16. Ismailov RM, Leatherdale ST. Smoking cessation aids and strategies among former smokers in Canada. Addict Behav 2010;35:282-5.

17. Nagelhout GE, de Korte-de Boer D, Kunst AE, et al. Trends in socioeconomic inequalities in smoking prevalence, consumption, initiation, and cessation between 2001 and 2008 in the Netherlands. Findings from a national population survey. BMC Public Health 2012;12:303.

18. Corsi DJ, Boyle MH, Lear SA, et al. Trends in smoking in Canada from 1950 to 2011: progression of the tobacco epidemic according to socioeconomic status and geography. Cancer Causes Control 2014;25:45-57.

19. West R, Raw M, McNeill A, et al. Healthcare interventions to promote and assist tobacco cessation: a review of efficacy, effectiveness and affordability for use in national guideline development. Addiction 2015;110:1388-403.

20. Moore D, Aveyard P, Connock M, et al. Effectiveness and safety of nicotine replacement therapy assisted reduction to stop smoking: systematic review and meta-analysis. BMJ 2009;338:b1024.

21. Biener L, Hargraves JL. A longitudinal study of electronic cigarette use among a population-based sample of adult smokers: association with smoking cessation and motivation to quit. Nicotine Tob Res 2015;17:127-33.

22. Hitchman SC, Brose LS, Brown J, et al. Associations between e-cigarette type, frequency of use, and quitting smoking: findings from a longitudinal online panel survey in Great Britain. Nicotine Tob Res 2015;17:1187-94.

23. Brose LS, Hitchman SC, Brown J, et al. Is the use of electronic cigarettes while smoking associated with smoking cessation attempts, cessation and reduced cigarette consumption? A survey with a 1-year follow-up. Addiction 2015;110:1160-8.

24. Vardavas CI, Filippidis FT, Agaku IT. Determinants and prevalence of e-cigarette use throughout the European Union: a secondary analysis of 26566 youth and adults from 27 Countries. Tob Control 2015;24:442-8. 